\title{
Ectopia lentis et pupillae: the genetic aspects and differential diagnosis
}

\author{
A Colley, I C Lloyd, A Ridgway, D Donnai
}

\begin{abstract}
Two sib pairs and a fifth child are described with autosomal recessive ectopia lentis et pupillae. Patients with this disorder need regular ophthalmic review, but do not have the skeletal and metabolic complications associated with other syndromes with ectopia lentis.
\end{abstract}

Dislocation of the lens not only causes visual disturbance but frequently is a sign that a subject has a systemic disorder. Ectopia lentis et pupillae, an abnormality characterised by displaced lenses and pupils, is a recessively inherited condition without associated systemic abnormalities and thus carries a different prognosis. We present three families, discuss the differential diagnosis, and emphasise the importance of recognising congenital ectopia lentis et pupillae for management.

\section{Case reports}

CASE 1

A male, born to a non-consanguineous English couple who had two normal sons and had had three first trimester spontaneous abortions, was the product of their sixth pregnancy and weighed $4250 \mathrm{~g}$ at term. The abnormal position of his pupils was noticed soon after birth by his mother. He attended a normal school but had learning and social difficulties and was referred for ophthalmic examination at the age of 9 years.

On examination he had temporal ectopia of both pupils (fig 1) with lens equators visible within the pupil on each side. The lenses themselves were small and displaced nasally with dehiscence of the zonule.

Department of Medical Genetics, St Mary's Hospital, Hathersage Road, Manchester M13 0JH.

A Colley, D Donnai

Manchester Royal Eye Hospital, Manchester M13 0JH.

I C Lloyd, A Ridgway

Correspondence to Dr Colley.

Received for publication 5 June 1990.

Revised version accepted for publication 7 February 1991.
There was vitreous in the anterior chamber temporal to both lenses. There was a visual acuity of $6 / 24$ in the right eye and $6 / 18$ in the left. This remained unchanged until the age of 14 years when the left eye developed a low degree of myopia and an alternating divergent squint was noted. At 18 years of age a lens opacity was seen at the nasal border of the right pupil and there was further subluxation of the lenses. At present he is registered as partially sighted.

On examination at 20 years of age his height was $173 \mathrm{~cm}$ (25th centile), head circumference $60 \mathrm{~cm}$ ( $>98$ th centile), and his upper to lower segment ratio was $1 \cdot 1$ ( $>98$ th centile). He had no other dysmorphic features, no signs of Marfan syndrome or a connective tissue disorder, and his urine amino acid screen was negative. Both parents have normal eyes and there is no relevant family history.

\section{CASES 2 AND 3}

Two male sibs of a non-consanguineous English couple were both born at term after normal pregnancies and deliveries. The mother noticed that the older boy had asymmetrically placed pupils at the age of 3 months and a 'flickering eye' at a few years of age.

His left pupil was inferiorly displaced appearing similar to an incomplete coloboma and his right lens was subluxated. The visual acuity in his right eye was $6 / 9+$ without a significant refractive error. Refraction of the left eye showed -10 diopters of myopia and the eye became amblyopic.

At the age of $7 \frac{1}{2}$ years he was coping well in a normal school. He had normal stature, no dysmorphic features, no clinical signs of Marfan syndrome, and urine amino acid screening was negative.

Examination of the younger brother (case 3 ) showed normally positioned pupils but by $2 \frac{1}{2}$ years there was iridodonesis and bilateral subluxation of the lenses. By $4 \frac{1}{2}$ years he required highly hypermetropic glasses and used the aphakic area of his pupils. His left lens (fig 2) was dislocated upwards with a relatively large aphakic area inferiorly and refraction of this eye showed +10 diopters of hypermetropia. His right lens was subluxated inferiorly with a smaller resultant aphakic area. Recently both lenses 


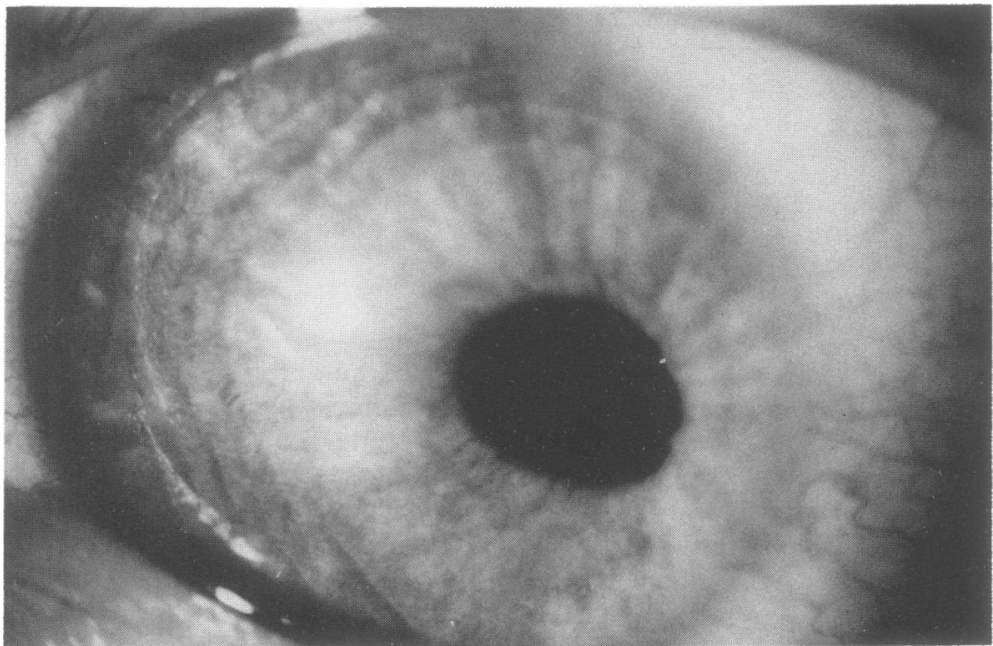

Figure 1 Left eye of case 1 showing temporal ectopia pupillae.

have become opaque and right vitreolensectomy has been performed.

He had normal stature and no dysmorphic features. Urine amino acid screens were negative. Both parents had normal eyes.

\section{CASES 4 AND 5}

Two male sibs were born to a non-consanguineous English couple. The older boy (case 4) was born at 36 weeks of gestation after a normal pregnancy. His mother noticed 'flickering' in both his eyes at the age of 3 months. Examination showed bilateral, inferiorly subluxated lenses with superonasal ectopia pupillae (fig 3). Intraocular pressure measurement showed abnormal pressures and he began topical antiglaucomatous medication. Corneal diameters were normal. Both optic discs were pink with no significant cupping but some degree of tilting. Gonioscopy showed bilateral gross abnormalities of the drainage angles. The iris was inserted directly into the sclerocornea and prominent iris processes were present. Contact lenses were prescribed. Visual acuity at the age of $2 \frac{1}{2}$ by preferential looking techniques was $20 / 600$ with both eyes.

The younger sib (case 5 ) was born at term after a normal pregnancy. His mother noted identical eye signs to those of his older brother and examination showed marked inferior subluxation of the right lens and slight inferior subluxation of the left.

On examination at the age of 18 months his right pupil was very slightly ectopic superonasally while

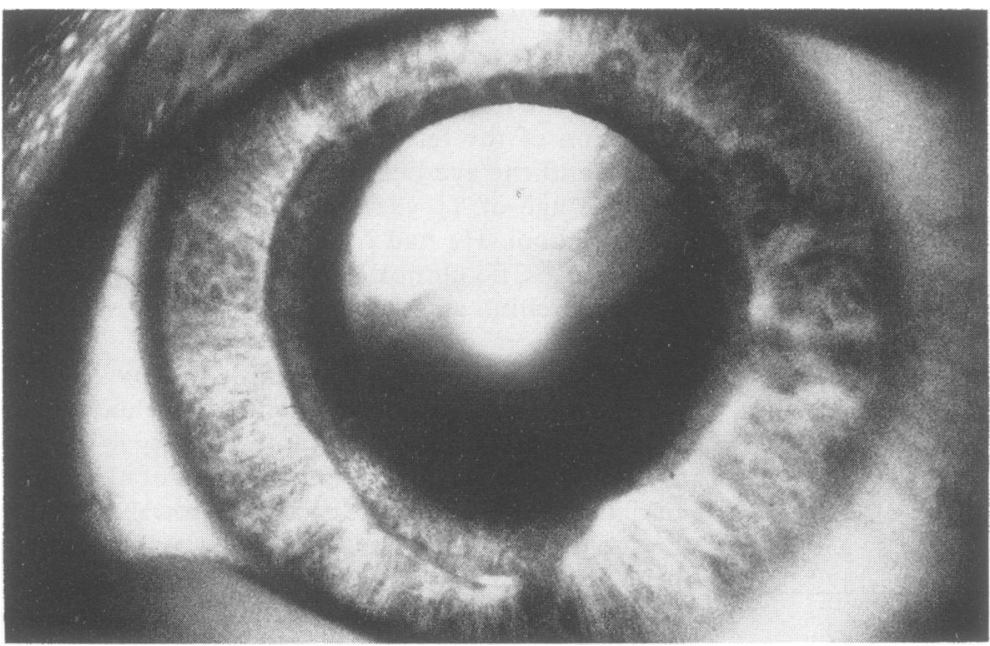

Figure 2 Left eye of case 3 with dilated pupil, showing upward dislocation of a cataractous lens. An abnormal pattern of the iris stroma is evident. 


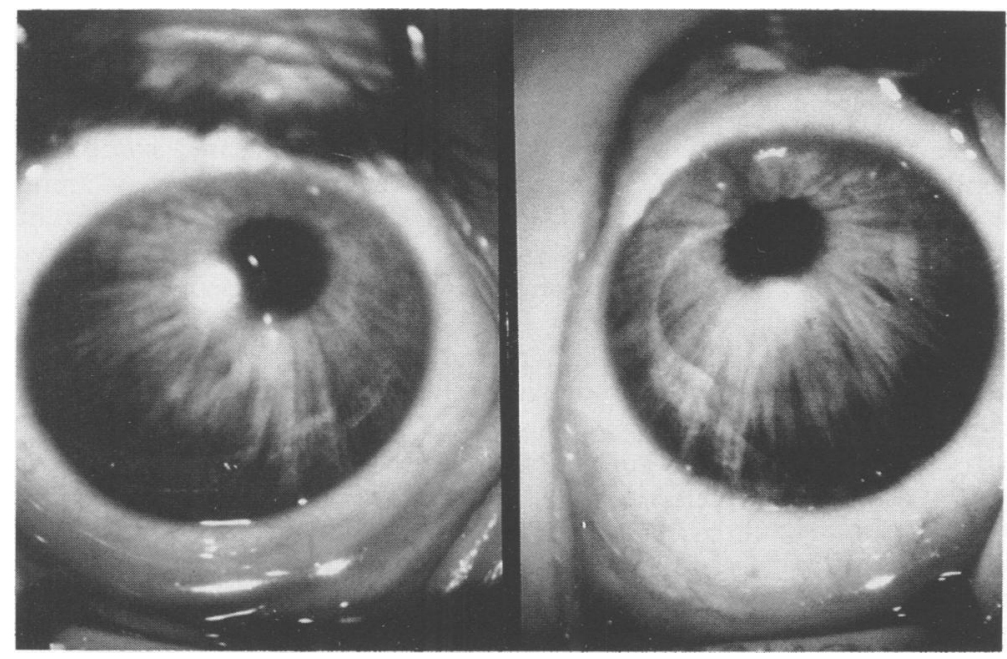

Figure 3 Right and left eyes of case 4 showing superonasal pupillary displacement.

the left was displaced superotemporally. Intraocular pressures were raised in both eyes and he required topical antiglaucomatous therapy. His corneal diameters were normal and both optic discs appeared healthy. Gonioscopy showed gross abnormality of the drainage angles with anterior iris insertion and no normal angle structures visible. Visual acuity by preferential looking techniques was $20 / 150$ bilaterally and contact lenses were needed to overcome the anisometropia.

Both sibs had normal stature and body proportions, no dysmorphic features, and normal development. There was no relevant family history and both parents, a sib, and half sib had normal eyes.

\section{Differential diagnosis}

The differential diagnosis of ectopia lentis et pupillae includes purely ocular abnormalities, as well as syndromes and metabolic disorders (table).

\section{Discussion}

The normal human pupil is displaced $0.5 \mathrm{~mm}$ inferiorly and nasally. Its displacement is often associated with progressive eye disease but may be congenital and non-progressive. In the latter situation, displacement of the lens is also often associated, but can be difficult to detect with the pupil undilated, so iridodonesis or a change in visual acuity or refraction may be an important clue. ${ }^{4}$

Ectopia lentis et pupillae was described in early 20th century German publications which amply showed autosomal recessive inheritance with multiple occurrences within sibships and unaffected but frequently consanguineous parents. Both eyes are usually affected and may be the mirror image of one
The differential diagnosis of ectopia lentis.

\begin{tabular}{|c|c|}
\hline Condition & Inheritance \\
\hline $\begin{array}{l}\text { Ocular disorders } \\
\text { Isolated ectopia lentis } \\
\text { Ectopia lentis et pupillae } \\
\text { Ectopia lentis, blepharoptosis, myopia } \\
\text { Ectopia lentis, keratoconus, cataracts }{ }^{3} \\
\text { Rieger's anomaly/syndrome } \\
\text { Microspherophakia } \\
\text { Uveal coloboma } \\
\text { Persistent hyperplastic vitreous } \\
\text { High myopia with buphthalmos } \\
\text { Intraocular infection } \\
\text { Ocular trauma } \\
\text { Iatrogenic, post eye surgery }\end{array}$ & $\begin{array}{c}\text { AD } \\
\text { AR } \\
\text { AD } \\
\text { Unknown } \\
-/ A D \\
\text { AR } \\
- \\
-\end{array}$ \\
\hline $\begin{array}{l}\text { Malformation syndromes } \\
\text { Marfan } \\
\text { Weill-Marchesani }\end{array}$ & $\begin{array}{l}\mathrm{AD} \\
\mathrm{AR}\end{array}$ \\
\hline $\begin{array}{l}\text { Metabolic disorders } \\
\text { Homocystinuria } \\
\text { Sulphite oxidase deficiency } \\
\text { Molybdenum cofactor deficiency } \\
\text { Hyperlysinaemia }\end{array}$ & $\begin{array}{l}\mathrm{AR} \\
\mathrm{AR} \\
\mathrm{AR} \\
\mathrm{AR}\end{array}$ \\
\hline $\begin{array}{l}\text { Rare associations } \\
\text { Ehlers-Danlos syndrome } \\
\text { Sturge-Weber sequence } \\
\text { Mandibulofacial dysostosis } \\
\text { Kniest syndrome } \\
\text { Crouzon syndrome } \\
\text { Refsum syndrome } \\
\text { Scleroderma }\end{array}$ & $\begin{array}{c}\mathrm{AD} \\
\overline{\mathrm{AD}} \\
\mathrm{AD} \\
\mathrm{AD} \\
\mathrm{AR} \\
-\end{array}$ \\
\hline
\end{tabular}

$\mathrm{AD}=$ autosomal dominant, $\mathrm{AR}=$ autosomal recessive, $-=$ sporadic.

another, although the condition can be unilateral. The pupils are often slit-like, ellipsoid, or oval. Affected pupils tend to be difficult to dilate owing to an atrophic, disrupted sphincter, and prominent iris processes are usually seen in the angle of the anterior chamber on gonioscopy. The pupils may be displaced in a direction opposite to that of the ectopic 
lenses and recent reports indicate that the lens may dislocate in any direction. ${ }^{5}$ Visual acuity is dependent upon the configuration of the pupil and the lens displacement.

In a recent series of 16 patients with ectopia lentis et pupillae, ${ }^{6}$ displacement of the pupils occurred in $60 \%$ of eyes, although a persistent pupillary membrane was seen in over $87 \%$. High myopia and tilting of the optic disc was reported in over $50 \%$. The corneal diameters may be enlarged and corneal astigmatism occurred in over a third of affected eyes. Cataracts also occur in approximately one third of affected eyes, and retinal detachment in $9 \%$. Glaucoma is not reported as particularly common; it is interesting that in two of our five cases (cases 4 and 5 ), there were gross abnormalities of the drainage angle with associated raised intraocular pressure.

Some members of a sibship may have simple ectopia lentis, while others in the same sibship have ectopia lentis et pupillae. ${ }^{3}$ This disparity can also be seen when comparing the two eyes of one subject. This variability may erroneously lead to a diagnosis of autosomal dominant simple ectopia lentis.

The pathogenesis of this syndrome is not fully understood. The iris musculature is absent in aniridia, absent in part in coloboma, and abnormally arranged in ectopia pupillae. This originally led to one theory that ectopia pupillae may represent part of a spectrum of iris abnormalities. More recently, abnormalities in neuroectodermal development have been postulated. ${ }^{6}$

Dislocation of the crystalline lens is an important diagnostic clue to a possible diagnosis of a syndrome or systemic disease. ${ }^{78}$ Subluxation of the lens may occur in any direction and a particular position is only suggestive, rather than diagnostic, of any specific condition. A geneticist frequently becomes involved because of the many inherited syndromes in which ectopia lentis is a cardinal feature. Accurate diagnosis of ectopia lentis et pupillae is important for risk assessment, prognosis, and management. The significant risk of visual impairment throughout life related to severe myopia, cataract, corneal astigmatism, and retinal detachment warrants regular ophthalmological follow up.

The authors wish to thank Mr M J A Britten for referring cases 2 and 3, Mrs J Noble for referring cases 4 and 5, Mr A Prest for medical illustrations, and Dr A Read for his patient translation of German publications.

1 Jaureguy BM, Hall JG. Isolated congenital ectopia lentis with autosomal dominant inheritance. Clin Genet 1979;15:97-109.

2 Gillum WN, Anderson RL. Dominantly inherited blepharoptosis, high myopia and ectopia lentis. Arch Ophthalmol 1982; 100:282-4.

3 Fielder AR. Paediatric ophthalmology: current aspects. New York: Dekker, 1983:165-76.

4 Cross HE. Ectopia lentis et pupillae. Am $\mathcal{f}$ Ophthalmol 1979; 88:381-4.

5 Nelson LB, Maumenee IH. Ectopia lentis. Surv Ophthalmol 1982;27:143-60.

6 Goldberg MF. Clinical manifestations of ectopia lentis et pupillae in 16 patients. Ophthalmology 1988;95:1080-7.

7 Cross HE, Jensen AD. Ocular manifestations in the Marfan syndrome and homocystinuria. Am $f$ Ophthalmol 1973; 82:405-20.

8 Pagon RA. Ophthalmic manifestations of metabolic disorders. Proc Greenwood Genetic Center 1989;8:97-107. 